\title{
Triamterene Enhances the Blood Pressure Lowering Effect of Hydrochlorothiazide in Patients with Hypertension
}

\author{
Wanzhu Tu, PhD ${ }^{1,3}$, Brian S. Decker, MD, PharmD2, Zangdong He, PhD', Blake L. Erdel, MD², \\ George J. Eckert, MA' , Richard N. Hellman, MD'2, Michael D. Murray, PharmD, MPH ${ }^{3,4}$, \\ John A. Oates, $M D^{5}$, and J Howard Pratt, $M D^{2}$
}

'Department of Biostatistics, Indiana University School of Medicine, Indianapolis, IN, USA; '² Department of Medicine, Indiana University School of Medicine, Indianapolis, IN, USA; ${ }^{3}$ Indiana University Center for Aging Research, Indianapolis, IN, USA; ${ }^{4}$ Purdue University College of Pharmacy, West Lafayette, IN, USA; ${ }^{5}$ Department of Medicine, Vanderbilt University Medical Center, Nashville, TN, USA.

\begin{abstract}
BACKGROUND: Triamterene, because of its potassiumsparing properties, is frequently used in combination with hydrochlorothiazide (HCTZ) to treat patients with hypertension. By inhibiting the epithelial sodium channel $(\mathrm{ENaC})$ in the cortical collecting duct, triamterene reduces potassium secretion, thus reducing the risk of hypokalemia. Whether triamterene has an independent effect on blood pressure (BP) has not been well studied.
\end{abstract}

OBJECTIVE: To determine if triamterene provides an effect to further lower BP in patients treated with HCTZ.

DESIGN: We conducted an observational study using electronic medical record data from the Indiana Network for Patient Care. Participants were 17,291 patients with the diagnosis of hypertension between 2004 and 2012.

MAIN MEASURES: BP was the primary outcome. We compared the BP between patients who were taking HCTZ, with and without triamterene, either alone or in combination with other antihypertensive medications, by using a propensity score analysis. For each medication combination, we estimated the propensity score (i.e., probability) of a patient receiving triamterene using a logistic regression model. Patients with similar propensity scores were stratified into subclasses and BP was compared between those taking triamterene or not within each subclass; the effect of triamterene was then assessed by combining BP differences estimated from all subclasses.

KEY RESULTS: The mean systolic BP in the triamterene + HCTZ group was $3.8 \mathrm{mmHg}$ lower than in the HCTZ only group $(p<0.0001)$; systolic BP was similarly lower for patients taking triamterene with other medication combinations. Systolic BP reduction was consistently observed for different medication combinations. The range of systolic $\mathrm{BP}$ reduction was between 1 and $4 \mathrm{~mm} \mathrm{Hg}$, depending on the concurrently used medications.

CONCLUSIONS: In the present study, triamterene was found to enhance the effect of HCTZ to lower BP. In addition to its potassium-sparing action, triamterene's ability to lower BP should also be considered.

Electronic supplementary material The online version of this article (doi:10.1007/s11606-015-3469-1) contains supplementary material, which is available to authorized users.

Received February 25, 2015

Revised June 15, 2015

Accepted July 1, 2015

Published online July 21, 2015
J Gen Intern Med 31(1):30-6

DOI: $10.1007 / \mathrm{s} 11606-015-3469-1$

(C) Society of General Internal Medicine 2015

\section{INTRODUCTION}

Diuretics are widely used for treatment of hypertension. ${ }^{1,2}$ In some individuals, diuretic-induced kaliuresis can result in hypokalemia and lead to cardiac disturbances and metabolic consequences. ${ }^{3-5}$ Hypokalemia is usually treated or prevented by combining the diuretic with an inhibitor of the epithelial sodium channel $(\mathrm{ENaC}){ }^{6,7}$ a membrane-bound ion channel that promotes sodium uptake and potassium secretion. In clinical practice, typical treatments include mineralocorticoid receptor (MR) antagonists that reduce potassium excretion by blocking aldosterone's upregulation of $\mathrm{ENaC}$, or direct $\mathrm{ENaC}$ inhibitors such as amiloride and triamterene. The MR antagonists and the direct inhibitors of $\mathrm{ENaC}$ are referred to as potassium-sparing diuretics.

Triamterene is a commonly prescribed potassium-sparing diuretic. ${ }^{8}$ Unlike amiloride and the aldosterone antagonists, whose respective antihypertensive properties have been well documented, ${ }^{9,10}$ the BP-lowering effect of triamterene has not been as clearly determined. In the few published studies of triamterene, it failed to show a consistent effect on BP beyond marginal reductions when high doses were used. ${ }^{11,12}$. A recent Cochrane Review of six studies, ${ }^{13}$ including two efficacy trials of triamterene with fewer than 150 patients each, ${ }^{14,15}$ reported no significant BP effects of triamterene.

There is, however, reason to believe that triamterene, as an $\mathrm{ENaC}$ inhibitor, should lower $\mathrm{BP}$. $\mathrm{ENaC}$ is thought to play a critical role in BP regulation. ${ }^{16}$ The level of ENaC activity is reciprocally linked to the state of sodium retention through aldosterone, and thus it can adjust to requirements for sodium. Residing in the distal nephron, $\mathrm{ENaC}$ is also anatomically positioned to make final adjustments to sodium balance. Nonetheless, the clinical decision to use triamterene is almost always based on its potassium-sparing properties and not on its potential to affect $\mathrm{BP}$.

By examining data from a large patient population, we sought to determine whether hydrochlorothiazide (HCTZ) 
combined with triamterene was associated with a lower BP than when HCTZ was used alone.

\section{METHOD}

\section{Subjects}

The study used clinical data from the Indiana Network for Patient Care (INPC), an electronic clinical information exchange formerly known as the Regenstrief Medical Record System (RMRS), which serves residents of metropolitan Indianapolis and surrounding counties. ${ }^{17,18}$ We searched clinical records in the INPC to identify individuals with the diagnosis of hypertension and then extracted BP measures and prescription records to determine the patients' medication use. All patient identifiers were removed before analysis. The Indiana University Institutional Review Board approved the study.

Hypertension cases were identified based on ICD9 code 401.9 (unspecified essential hypertension), 401.1 (benign essential hypertension), 401.0 (malignant essential hypertension), 255.10 (hyperaldosteronism, unspecified), 405.0 (malignant secondary hypertension), and 405.9 (unspecified secondary hypertension). Previous studies showed that ICD9 code had high specificity $(\sim 95 \%)$ and positive predictive value $(\sim 97 \%)$ in identifying hypertension cases. ${ }^{19}$ Following the Health Insurance Portability and Accountability Act of 1996 (HIPPA) against disclosure of dates of clinical visits, we used the date of the first recorded hypertension diagnosis in a given patient as an index date for that individual; dates of all subsequent clinical visits and medication prescriptions by the patient were coded as days from the index date. This coding system allowed us to determine the time sequence of hypertension treatment and BP measurement without revealing the actual clinical visit and prescription dates.

\section{Patient Characteristics}

We obtained the clinical records from identified hypertension cases between 2004 and 2012. Specifically, we extracted relevant demographic and clinical information including age, sex, race, and major comorbidities (using recorded ICD9 codes), including diabetes mellitus, chronic kidney disease, coronary artery disease, myocardial infarction, congestive heart failure, atrial fibrillation, hyperlipidemia, stroke, chronic obstructive pulmonary disease, and depression. BP measures in the patient medical records were also extracted for analysis.

\section{Prescription Data}

INPC receives medication dispensing data from Surescripts ${ }^{\circledR}$, a nationwide pharmacy claim network that connects pharmacies, payers, hospitals, physicians, and health information exchanges. ${ }^{20}$ All prescription medications were identified by the National Drug Code (NDC), a unique product identifier used in the United States for drugs intended for human use. We used the Medi-Span ${ }^{\circledR}$ software to classify the extracted NDC code into specific classes of medications (Medi-Span. Master Drug Data Base Documentation Manual. Indianapolis, IN: Medi-Span; 2007.)

Classes of drugs that were deemed relevant to hypertensive treatments were reviewed, categorized and considered in the current analysis, including thiazide diuretics, loop diuretics, adrenergic antagonists, angiotensin-converting enzyme (ACE) inhibitors, angiotensin receptor blockers (ARBs), calcium channel blockers (CCBs), and direct vasodilators. Inhibitors of $\mathrm{ENaC}$ other than triamterene, such as spironolactone and eplerenone, were excluded in the analysis. Combination drugs were counted as multiple drugs. For example, Maxzide- $25^{\text {TM }}$ (triamterene/HCTZ) was counted as two individual drugs: $37.5 \mathrm{mg}$ triamterene and $25 \mathrm{mg}$ HCTZ.

We also compared the prescription orders as well as the pharmacy dispensing records, when both were available, to verify the dose prescribed and dispensed amount. In our study, most of the patients received care at Eskenazi Health (formerly Wishard Health), which dispensed HCTZ and triamterene in $50 \mathrm{mg}$ and $75 \mathrm{mg}$ tablets, respectively. Patients who received HCTZ $50 \mathrm{mg}$ and triamterene $75 \mathrm{mg}$ were instructed to cut the pills in half before consumption.

\section{Analysis}

We first evaluated the numbers of patients on different drugs or drug combinations. We compared BP in patients prescribed the same drugs with and without triamterene. For example, we compared the BP in patients prescribed HCTZ alone with the BP in those patients prescribed HCTZ plus triamterene. Similarly, the $\mathrm{BP}$ in patients prescribed an ACE inhibitor and a betablocker were compared with the BP in those prescribed the same classes of drugs plus triamterene. We chose to compare the $\mathrm{BP}$ in matched drug groups to alleviate the potential confounding effects of different antihypertensive agents. For example, we did not compare patients prescribed HCTZ and triamterene with those prescribed HCTZ and an ACE inhibitor. Such a drug-specific analytical strategy limited the sample sizes in each comparison. As a result, we were able to determine the BP effects of triamterene in only a few commonly encountered drug classes.

A challenge in analyzing the observed clinical records was the lack of random drug assignment. The lack of treatment randomization makes it difficult to causally attribute the observed BP differences to triamterene. To remedy this, we performed a propensity score analysis, which is a commonly accepted approach for alleviating confounding effects in observational studies; this method has been used frequently in pharmacoepidemiologic research. ${ }^{21,22}$ Propensity score analysis is based on the premise that unbiased treatment effect estimates can be achieved by comparing patients with similar propensity of receiving a particular treatment. ${ }^{23}$ Therefore, by 
estimating the probabilities of individual patients receiving the treatment (i.e., propensity scores), and then stratifying patients into subclasses based on the estimated propensity scores, one creates comparable groups from which unbiased treatment effects can be estimated. Final estimation is ascertained by combining estimates from all subclasses using a weighted average formula. ${ }^{24}$ In this research, for each drug or drug combination, we used a logistic regression model to estimate each patient's propensity score, i.e., the probability of being prescribed triamterene. The logistic regression models included all patient characteristics listed in Table 1. We then stratified patients based on their estimated propensity scores; patients with similar propensity scores were put into the same subclass and BP was compared between those prescribed triamterene and those not prescribed triamterene. Following the generally accepted practice of propensity score analysis, we divided the patients into propensity score quartiles, i.e., four subclasses. Triamterene effects on BP were first determined within each subclass and then combined into an overall treatment effect estimate. All subjects with BP assessments were included in the analysis. To ensure that the propensity analysis resulted in comparable subclasses, we carefully examined the patient characteristics and the propensity score distributions within each subclass. All intermediate results are presented in an appendix of the Supplemental material. An alternative method for assessing the effects of triamterene was to conduct regression analysis adjusting for the effects of covariates. We performed regression analysis for each of the drug groups. The findings were consistent with those from the propensity score analysis. We examined the

Table 1. Demographic and Clinical Characteristics of the Study Subjects

\begin{tabular}{|c|c|c|c|}
\hline \multirow[t]{2}{*}{ Patient characteristics } & \multirow{2}{*}{$\begin{array}{l}\begin{array}{l}\text { Without } \\
\text { triamterene }\end{array} \\
N=14,160\end{array}$} & \multirow{2}{*}{$\begin{array}{l}\begin{array}{l}\text { With } \\
\text { triamterene }\end{array} \\
N=3131\end{array}$} & \multirow[t]{2}{*}{ p values } \\
\hline & & & \\
\hline $\begin{array}{l}\text { Age at first recorded } \\
\text { hypertension } \\
\text { diagnosis }\end{array}$ & $50.7 \pm 13.4$ & $50.8 \pm 12.8$ & 0.8282 \\
\hline Female & $9253(65.3 \%)$ & $2405(76.8 \%)$ & $<0.0001$ \\
\hline Black race & $8107(57.3 \%)$ & $2085(66.6 \%)$ & $<0.0001$ \\
\hline Diabetes & $4709(33.3 \%)$ & $892(28.5 \%)$ & $<0.0001$ \\
\hline Chronic kidney disease & $1188(8.4 \%)$ & $250(8 \%)$ & 0.4575 \\
\hline Coronary artery disease & $2024(14.3 \%)$ & $368(11.8 \%)$ & 0.0002 \\
\hline Myocardial infarction & $670(4.7 \%)$ & $115(3.7 \%)$ & 0.0100 \\
\hline Congestive heart failure & $1316(9.3 \%)$ & $214(6.8 \%)$ & $<0.0001$ \\
\hline Hyperlipidemia & $5433(38.4 \%)$ & $1230(39.3 \%)$ & 0.3406 \\
\hline Atrial fibrillation & $567(4 \%)$ & $116(3.7 \%)$ & 0.4364 \\
\hline Stroke & $641(4.5 \%)$ & $110(3.5 \%)$ & 0.0118 \\
\hline $\begin{array}{l}\text { Chronic obstructive } \\
\text { pulmonary disease }\end{array}$ & $1940(13.7 \%)$ & $362(11.6 \%)$ & 0.0014 \\
\hline Depression & $3184(22.5 \%)$ & $697(22.3 \%)$ & 0.7852 \\
\hline $\begin{array}{l}\text { Years since first } \\
\text { hypertension } \\
\text { treatment }\end{array}$ & $3.3 \pm 4.2$ & $3.1 \pm 4.1$ & 0.0720 \\
\hline
\end{tabular}

potassium levels before and after a patient received triamterene.

\section{RESULTS}

We identified 17,291 patients prescribed HCTZ (or a combination including HCTZ), of whom 3131 patients were prescribed triamterene. The median dose of HCTZ was $25 \mathrm{mg}$ for both treatment groups. The median dose of triamterene was $37.5 \mathrm{mg}$ for the triamterene group.

Patient demographic and clinical characteristics were presented in Table 1. Briefly, patients prescribed triamterene were more likely to be female ( $77 \%$ vs. $65 \% ; p<0.0001$ ), more likely African-American (67\% vs. $57 \%$; $<0.0001$ ), less likely to have diabetes ( $29 \%$ vs. $34 \% ; p<0.0001)$, coronary artery disease ( $12 \%$ vs. $14 \% ; p=0.0004)$, myocardial infarction ( $4 \%$ vs. $5 \%$; $=0.01$ ), heart failure ( $7 \%$ vs. $9 \%$; $p<0.0001$ ), stroke ( $4 \%$ vs. $5 \% ; p=0.0118$ ), and chronic obstructive pulmonary disease ( $12 \%$ vs $14 \% ; p=0.0014)$. Because of the relatively large sample size, we detected significant differences in comorbidities between the patients prescribed and not prescribed triamterene. With the exception of those with diabetes, the observed prevalence rates of these comorbidities tended to be small, usually less than $2 \%$. In the subsequent propensity score analysis, we took these differences into account for the propensity score.

The distributions of the estimated propensity scores in the two treatment groups had sufficient overlap (see Appendix), which ensured adequate numbers of patients in each subclass for the estimation of within-subclass triamterene effects. The balance of patient characteristics within each subclass was examined and within-subclass treatment effects were obtained. All intermediate results were included in the online Supplement. For treatment effect estimates, we used all patients available for each subclass; no patients were excluded in the process of propensity score subclassification. Combined treatment effects, i.e., the estimated triamterene effects on systolic and diastolic BP for different drug combinations are reported in Tables 2 and 3. Estimated triamterene effects for all major drug class combinations are presented graphically in Figure 1.

For each of the comparators below, statistically significant differences were found for systolic BP, but none were significant for diastolic BP.

\section{HCTZ}

We first compared BP in patients prescribed HCTZ, with and without triamterene. For each subclass, we calculated the mean differences in systolic and diastolic BP between patients on HCTZ alone and those on HCTZ and triamterene. Aggregating the results in the four propensity score subclasses, we obtained a combined BP difference; mean systolic BP in patients prescribed triamterene was $3.8 \mathrm{mmHg}$ lower than that in patients prescribed HCTZ alone (135.75 vs. $131.32 \mathrm{mmHg}$; $p<0.0001)$. The difference in diastolic BP did not reach the 
Table 2. Estimated Effects of Triamterene on Systolic BP by Drug Class: Hydrochlorothiazide (HCTZ), Angiotensin-converting enzyme (ACE) inhibitor, Beta-blocker (BB), Calcium channel blocker (CCB)

\begin{tabular}{|c|c|c|c|c|c|c|}
\hline Drug combinations & $\begin{array}{l}\text { Number of patients } \\
\text { who did not receive } \\
\text { triamterene }\end{array}$ & $\begin{array}{l}\text { Mean SBP of } \\
\text { patients who did } \\
\text { not receive } \\
\text { triamterene (SD) }\end{array}$ & $\begin{array}{l}\text { Number of } \\
\text { patients who } \\
\text { received } \\
\text { triamterene }\end{array}$ & $\begin{array}{l}\text { Mean SBP of } \\
\text { patients who } \\
\text { received } \\
\text { triamterene (SD) }\end{array}$ & $\begin{array}{l}\text { Estimated effect } \\
\text { on systolic BP } \\
\text { from propensity } \\
\text { score analysis (SD) }\end{array}$ & p value \\
\hline HCTZ & 1865 & 135.75 & 49 & 131.32 & 3.80 & 0.0001 \\
\hline $\mathrm{HCTZ}+\mathrm{ACE}$ & 1867 & $136.11(14.61)$ & 255 & $132.91(13.29)$ & $2.40(1.15)$ & 0.0365 \\
\hline $\mathrm{HCTZ}+\mathrm{ACE}+\mathrm{CCB}$ & 1174 & $142.24(15.54)$ & 239 & $138.50(13.66)$ & $2.97(0.98)$ & 0.0024 \\
\hline $\mathrm{HCTZ}+\mathrm{ACE}+\mathrm{BB}+\mathrm{CCB}$ & 1228 & $143.15(15.71)$ & 270 & $140.07(14.04)$ & $3.50(1.22)$ & 0.0039 \\
\hline All drug combinations & 14,147 & $139.02(15.23)$ & 3131 & $136.91(14.69)$ & $1.84(0.29)$ & $<0.0001$ \\
\hline
\end{tabular}

level of statistical significance $(81.27$ vs. $79.74 \mathrm{mmHg}$; $p=0.1029)$. The BP differences are shown graphically in Figure 1.

To verify our findings, we used regression analyses to assess the triamterene effect by adjusting for the patient characteristics, and by adjusting propensity scores. Both analyses showed significantly lower systolic BP in patients prescribed HCTZ and triamterene, as compared to patients prescribed HCTZ alone. The mean magnitude of BP reduction was about $3.8 \mathrm{mmHg}$ (SD $0.70 \mathrm{mmHg}, p<0.0001$ ), after adjusting for the effects of patient demographics and major comorbidities.

\section{HCTZ + ACE inhibitor}

There were 1870 patients who were prescribed HCTZ + ACE inhibitor and 255 who were prescribed the same classes of medications and triamterene. We used a logistic regression model to estimate the propensity for individual patients to be prescribed triamterene. Stratifying the patients based on their propensity scores, we calculated the mean systolic and diastolic BP in each subclass. Combining the treatment effects from all subclasses, we noted that the mean systolic BP was $2.4 \mathrm{mmHg}$ lower in those taking triamterene (SD $1.15 \mathrm{mmHg}$, $p=0.0365$ ). Regression analysis adjusting for patient characteristics confirmed this finding (beta $=2.2, \mathrm{SD}=0.94, p=0.0213$ ).

\section{HCTZ + ACE inhibitor + CCB}

We identified 1175 patients who were prescribed HCTZ, an ACE inhibitor, and a CCB; 239 patients were prescribed the same drugs plus triamterene. Using a propensity score subclassification, we first analyzed the BP differences within the subclasses, and then combined treatment effect estimates for an overall effect of triamterene. The mean systolic BP in the triamterene group was $3.0 \mathrm{mmHg}$ lower (SD $0.979 \mathrm{mmHg}$, $p=0.0024)$.

\section{HCTZ + ACE inhibitor + beta blocker + CCB}

We identified 1229 patients who were prescribed HCTZ + $\mathrm{ACE}$ inhibitor $+\mathrm{BB}+\mathrm{CCB}$ and 270 were prescribed the same classes of medications plus triamterene. Combining the treatment effects estimated from the subclasses, we noted that the mean systolic BP was $3.5 \mathrm{mmHg}$ lower in patients prescribed triamterene (SD $1.2 \mathrm{mmHg}, p=0.0039$ ). Regression analysis adjusting for patient characteristics confirmed this finding (beta=3.155, $\mathrm{SD}=1.0103, p=0.0018$ ).

\section{HCTZ + all other medications}

There were numerous combinations of antihypertensive medications used concurrently with HCTZ. However, the numbers of patients within each of these drug combinations tended to be small. To analyze, we included all of the patients prescribed those combinations in this analysis. In total, we identified 8019 patients who were prescribed HCTZ and some other combinations of antihypertensives, and 1869 patients who were prescribed the same classes of medications and triamterene. Analysis showed that systolic BP was on average $1.1 \mathrm{mmHg}$ lower in those taking triamterene (SD $0.39 \mathrm{mmHg}$; $p=0.0050$ ).

Finally, we examined the plasma levels of potassium in study patients when available. The overall potassium levels between the two groups were identical $(4.2 \mathrm{mmol} / \mathrm{L})$. For patients who were prescribed triamterene, we examined their potassium levels before and after the initiation of triamterene.

Table 3. Estimated Effects of Triamterene on Diastolic BP by Drug Class: Hydrochlorothiazide (HCTZ), Angiotensin-converting Enzyme (ACE) Inhibitor, Beta-blocker (BB), Calcium Channel Blocker (CCB)

\begin{tabular}{lllll}
\hline \hline Drug combinations & $\begin{array}{l}\text { Number of patients } \\
\text { who did not receive } \\
\text { triamterene }\end{array}$ & $\begin{array}{l}\text { Mean DBP of } \\
\text { patients who did } \\
\text { not receive } \\
\text { triamterene (SD) }\end{array}$ & $\begin{array}{l}\text { Number of } \\
\text { patients who } \\
\text { received } \\
\text { triamterene }\end{array}$ & $\begin{array}{l}\text { Mean DBP of } \\
\text { patients who } \\
\text { received } \\
\text { triamterene (SD) }\end{array}$ \\
\hline HCTZ & 1867 & $81.27(10.13)$ & 498 & $\begin{array}{l}\text { Estimated effect } \\
\text { on diastolic BP } \\
\text { from propensity } \\
\text { score analysis (SD) }\end{array}$ \\
HCTZ + ACE & 1870 & $79.57(10.51)$ & 255 & $79.74(9.47)$ \\
HCTZ + ACE + CCB & 1174 & $81.95(11.05)$ & 239 & $79.06(9.62)$ \\
HCTZ + ACE + BB + CCB & 1229 & $80.94(11.25)$ & 270 & $0.90(0.55)$ \\
All drug combinations & 14,159 & $80.18(10.82)$ & 3131 & $0.002(0.94)$ \\
\hline
\end{tabular}



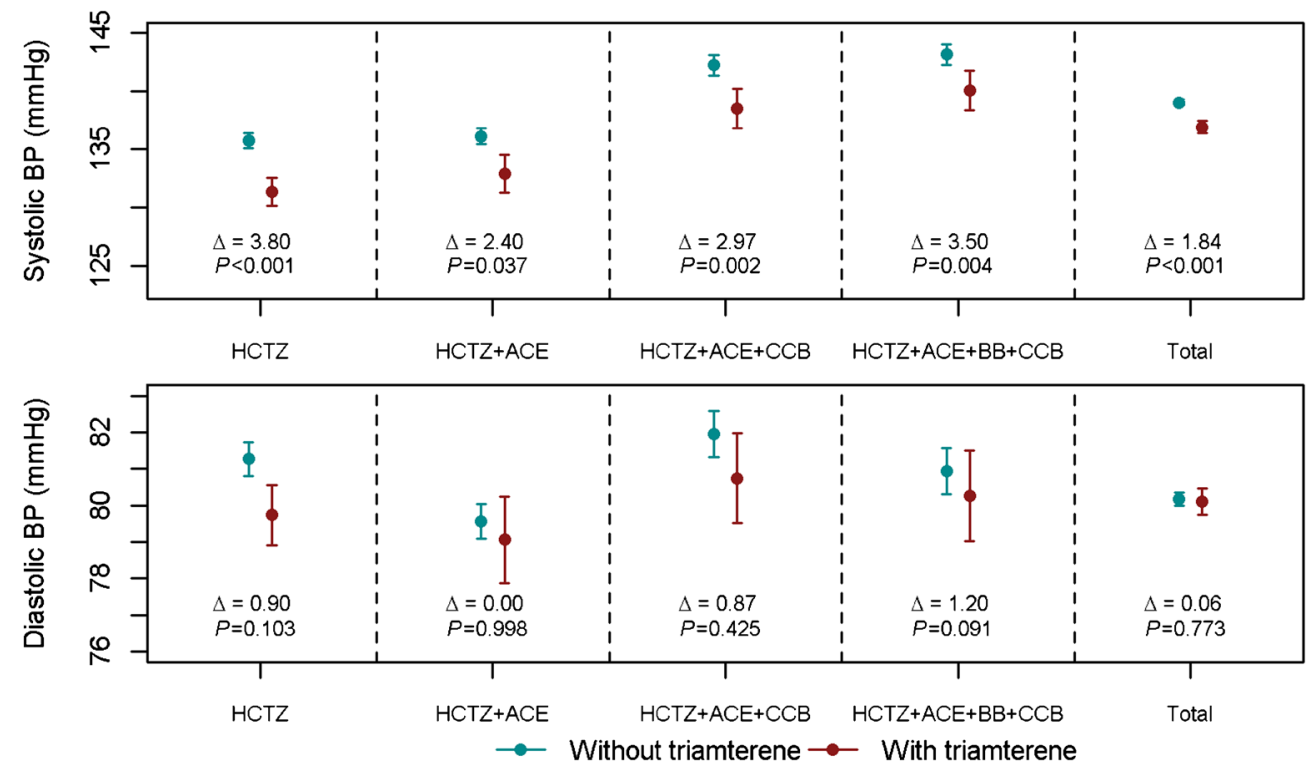

Figure 1. Mean systolic and diastolic BP, and corresponding $95 \%$ confidence intervals of mean BP in patients treated with and without triamterene. BP differences between those who received and those who did not receive estimated triamterene were obtained from propensity score analysis. Data are shown by drug class.

In our study data, potassium levels increased after patients were put on triamterene, but the increase was small $(0.03 \mathrm{mmol} / \mathrm{L})$ and not statistically significant $(p=0.16)$.

\section{DISCUSSION}

In our study, triamterene used in combination with HCTZ, presumably prescribed for its potassium-sparing properties, was found to provide an added BP-lowering effect. We found that systolic BP was $3.8 \mathrm{~mm} \mathrm{Hg}$ lower in those who were treated with HCTZ and triamterene as opposed to those treated with HCTZ alone. When all drug combinations are considered, the difference was $1.8 \mathrm{~mm} \mathrm{Hg}$. Effects of such magnitude, although modest, are not drastically dissimilar to the observed systolic BP effects of ACE inhibitors, (3-6 mm $\mathrm{Hg}),{ }^{25,26}$ calcium channel blockers $(5 \mathrm{~mm} \mathrm{Hg}),{ }^{27}$ betaadrenergic blockers $(3.8-4 \mathrm{~mm} \mathrm{Hg}),{ }^{28,29}$ when they were compared against placebo controls. Importantly, these reported differences were further reduced when these drugs were compared against other antihypertensive agents. ${ }^{30-32}$ Viewed within this context, the magnitude of BP reduction associated with the addition of triamterene was certainly not trivial. This difference was also comparable to what was observed when sodium intake was reduced from high to intermediate levels in the Dietary Approaches to Stop Hypertension (DASH) trial. ${ }^{33}$ When considered in population-scale proportions, such an effect on BP would be expected to produce a substantial reduction in cardiovascular morbidity, ${ }^{34}$ as well as the benefits derived from less frequent hypokalemia. It may have, for example, contributed to the previously reported reduction in cardiovascular-related mortality, including sudden death in elderly hypertensive patients treated with ENaC inhibitors. ${ }^{35}$ The findings of the present study would appear to generate an additional rationale for considering the inclusion of triamterene in the treatment of hypertension.

Data from randomized clinical trials evaluating the BP effects of low doses of triamterene as monotherapy in patients with hypertension have not been forthcoming. A recent Cochrane Collaboration study reported little evidence that triamterene, or for that matter, amiloride, affected BP. ${ }^{8}$ Interestingly, among the trials reviewed by the Cochrane report were two randomized trials of triamterene $50 \mathrm{mg}$ plus chlorthalidone $25 \mathrm{mg}$ or $50 \mathrm{mg}$, with 129 and 141 patients, respectively. ${ }^{14,15}$ Neither study found significant BP benefit associated with the addition of triamterene. Conversely, our study found a significant, albeit modest, reduction in BP with the addition of triamterene at a lower dose, and the effect was consistent across several major drug classes. The difference in findings may be due to the much larger sample size we were able to analyze in this study. Considering the large variability of BP, it is difficult for studies with small sample sizes to find moderate differences in BP. However, small studies using triamterene at much higher doses (100-400 mg per day) did show that triamterene had mild antihypertensive properties in comparison to HCTZ or chlorthalidone. ${ }^{8,11,12,36,37}$ Consistent with the current findings, a previous study reported that the addition of amiloride lowered systolic BP significantly in African Americans with uncontrolled low-renin hypertension treated with either HCTZ or furosemide and a calcium channel blocker ${ }^{9}$. Differences in the doses of drugs, severity of hypertension, and race may have contributed to the variable conclusions as to the BP effects of triamterene. 
Although triamterene lowered BP, purportedly by decreasing sodium reabsorption, there may be an effect of increasing serum potassium levels on $\mathrm{BP} .{ }^{8} \mathrm{ENaC}$ inhibitors, upon reaching the cortical collecting duct, act directly on the channel to affect the transport of sodium. The available direct inhibitors, triamterene and amiloride, have been shown to reduce the activity of $\mathrm{ENaC}$ by raising potassium levels. In the current study, only a fraction of the patients had sequential serum potassium measurements that could be used to examine the sequential changes in potassium levels associated with triamterene. In the subset of patients with longitudinal serum potassium measurements, we did observe a slight increase in potassium levels after patients were put on triamterene. However, the inherent limitations of medical record data did not permit us to adequately assess the long-term clinical consequences of potassium-sparing effects of triamterene.

Another limitation of the current report was that the findings were derived from observational data and not from a randomized trial. Considering the differences in patient characteristics, propensity score analysis is unlikely to completely remove the various confounding effects. Additionally, the propensity score method does not guarantee a causal interpretation, especially when there are unmeasured or imperfectly measured confounders. Nonetheless, the consistency of the results across comparator groups gives more credence to the BP-lowering effect of triamterene. Although we do not know with certainty why triamterene was prescribed in a given individual, it is not illogical to assume that the great majority of the prescriptions were made for triamterene's potassiumsparing actions. Serum potassium levels were similar in the two groups and not, as one might anticipate, higher in those who also received triamterene. One explanation is that HCTZtreated patients who developed hypokalemia would in all likelihood be given triamterene more often than HCTZtreated patients who did not develop hypokalemia. Other limitations include lack of information on the timing of the benefits, potential risk exposure misclassification, and unknown generalizability of the study findings.

Notwithstanding these limitations, this may be the first large-scale study that provides observationally derived evidence that triamterene at the commonly prescribed dose of $37.5 \mathrm{mg}$ was associated with a lower systolic BP in individuals with hypertension. The likelihood of a superior antihypertensive response to the combination of triamterene with HCTZ should be considered when selecting diuretics for the treatment of hypertension.

Acknowledgements: Contributors: The research was made possible by the technical support of the Center for Biomedical Informatics, Regenstrief Institute, Inc. The authors thank Ms Jane Wang and Faye Smith for data management support.

Conflict of Interest: The authors declare that they do not have a conflict of interest.

Funders: This work was in part supported by a National Heart, Lung, and Blood Institute grant R01 HL095086 (Tu and Pratt), and a
Veteran's Administration merit award (Pratt). The research data were extracted from the Indiana Network for Patient Care with support of a grant under the Merck-Regenstrief Program in Personalized Health Care Research and Innovation, a collaboration between Merck, Sharp and Dohme and the Regenstrief Institute, Inc. The funding sources had no role in the design and conduct of the study; collection, management, analysis, and interpretation of the data; preparation, review, or approval of the manuscript; and the decision to submit the manuscript for publication.

Corresponding Author: Wanzhu Tu, PhD; Department of BiostatisticsIndiana University School of Medicine, 410 West 10th Street, Indianapolis, IN 46202, USA (e-mail: wtu1@iu.edu).

\section{REFERENCES}

1. James PA, Oparil S, Carter BL, et al. 2014 evidence-based guideline for the management of high blood pressure in adults: report from the panel members appointed to the Eighth Joint National Committee (JNC 8). JAMA. 2014;311(5):507-20.

2. Ernst ME, Moser M. Use of diuretics in patients with hypertension. N Engl J Med. 2009;361(22):2153-64.

3. Hoes AW, Grobbee DE, Lubsen J, Man in 't Veld AJ, van der Does E, Hofman A. Diuretics, beta-blockers, and the risk for sudden cardiac death in hypertensive patients. Ann Intern Med. 1995;123(7):481-7.

4. Runyan JW Jr. Influence of thiazide diuretics on carbohydrate metabolism in patients with mild diabetes. N Engl J Med. 1962;267:541-3.

5. Rowe JW, Tobin JD, Rosa RM, Andres R. Effect of experimental potassium deficiency on glucose and insulin metabolism. Metabolism. 1980;29(6):498-502.

6. Rossier BC, Schild L. Epithelial sodium channel: Mendelian versus essential hypertension. Hypertension. 2008;52(4):595-600.

7. Moser M, Feig PU. Fifty years of thiazide diuretic therapy for hypertension. Arch Intern Med. 2009;169(20):1851-6.

8. Schnaper HW, Freis ED, Friedman RG, et al. Potassium restoration in hypertensive patients made hypokalemic by hydrochlorothiazide. Arch Intern Med. 1989; 149(12):2677-81.

9. Saha C, Eckert GJ, Ambrosius WT, et al. Improvement in blood pressure with inhibition of the epithelial sodium channel in blacks with hypertension. Hypertension. 2005;46(3):481-7.

10. Guichard JL, Clark D 3rd, Calhoun DA, Ahmed MI. Aldosterone receptor antagonists: current perspectives and therapies. Vasc Health Risk Manag. 2013;9:321-31

11. Spiekerman RE, Berge KG, Thurber DL, Gedge SW, McGuckin WF. Potassium-sparing effects of triamterene in the treatment of hypertension. Circulation. 1966;34(3):524-31.

12. Keim HJ, Drayer JI, Thurston H, Laragh JH. Triamterene-induced changes in aldosterone and renin values in essential hypertension. Evidence of a role for aldosterone in preventing blood pressure reduction. Arch Intern Med. 1976;136(6):645-8.

13. Heran BS, Chen JM, Wang JJ, Wright JM. Blood pressure lowering efficacy of potassium-sparing diuretics (that block the epithelial sodium channel) for primary hypertension. Cochrane Database Syst Rev. 2012;11, CD008167.

14. Webb EL, Godfrey JC, Gertel A, et al. The efficacy of a potassium-sparing combination of chlorthalidone and triamterene in the control of mild and moderate hypertension. I. J Int Med Res. 1984;12(3):133-9.

15. Webb EL, Godfrey JC, Rosenbaum R, Zisblatt M, Vukovich RA, Neiss ES. Chlorthalidone-triamterene: a potassium-sparing diuretic combination for the treatment of oedema. J Int Med Res. 1984;12(3):147-53.

16. Pratt JH. Central Role for ENaC in Development of Hypertension. J Am Soc Nephrol. 2005; 16(11):3154-9.

17. McDonald CJ, Overhage JM, Tierney WM, et al. The Regenstrief Medical Record System: a quarter century experience. Int J Med Inform. 1999;54(3):225-53.

18. McDonald CJ, Overhage JM, Barnes M, et al. The Indiana network for patient care: a working local health information infrastructure. An example of a working infrastructure collaboration that links data from five health systems and hundreds of millions of entries. Health Aff. 2005;24(5):121420 .

19. Birman-Deych E, Waterman AD, Yan Y, Nilasena DS, Radford MJ, Gage BF. Accuracy of ICD-9-CM codes for identifying cardiovascular and stroke risk factors. Med Care. 2005;43(5):480-5. 
20. Grossman JM, Gerland A, Reed MC, Fahlman C. Physicians' experiences using commercial e-prescribing systems. Health Aff. 2007;26(3):w393-404.

21. Perkins SM, Tu W, Underhill MG, Zhou XH, Murray MD. The use of propensity scores in pharmacoepidemiologic research. Pharmacoepidemiol Drug Saf. 2000;9(2):93-101.

22. Rubin DB. Estimating causal effects from large data sets using propensity scores. Ann Intern Med. 1997;127(8_Part_2):757-63.

23. Rosenbaum PR, Rubin DB. The central role of the propensity score in observational studies for causal effects. Biometrika. 1983;70(1):41-55.

24. Austin PC. An Introduction to Propensity Score Methods for Reducing the Effects of Confounding in Observational Studies. Multivar Behav Res. 2011;46(3):399-424.

25. Yusuf S, Sleight P, Pogue J, Bosch J, Davies R, Dagenais G. Effects of an angiotensin-converting-enzyme inhibitor, ramipril, on cardiovascular events in high-risk patients. The Heart Outcomes Prevention Evaluation Study Investigators. N Engl J Med. 2000;342(3):145-53.

26. MacMahon S, Sharpe N, Gamble G, et al. Randomized, placebo-controlled trial of the angiotensin-converting enzyme inhibitor, ramipril, in patients with coronary or other occlusive arterial disease. J Am Coll Cardiol. 2000;36(2):438-43.

27. Pitt B, Byington RP, Furberg CD, et al. Effect of amlodipine on the progression of atherosclerosis and the occurrence of clinical events. Circulation. 2000; 102(13): 1503-10.

28. Buhler F. Cardiovascular risk and risk-factors in a randomized trial of treatment based on the beta-blocker oxprenolol - The International Prospective Primary Prevention Study in Hyptertension (IPPPSH). J Hypertens. 1985;3(4):379-92.

29. Eriksson S, Olofsson B, Wester P. Atenolol in secondary prevention after stroke. Cerebrovasc Dis. 1995;5(1):21-5.
30. Collaboration BPLTT. Effects of ACE inhibitors, calcium antagonists, and other blood-pressure-lowering drugs: results of prospectively designed overviews of randomised trials. Lancet. 2000;356(9246):195564.

31. Dahlöf B, Devereux RB, Kjeldsen SE, et al. Cardiovascular morbidity and mortality in the Losartan Intervention For Endpoint reduction in hypertension study (LIFE): a randomised trial against atenolol. Lancet. 2002;359(9311):995-1003.

32. Zanchetti A, Bond MG, Hennig M, et al. Calcium antagonist lacidipine slows down progression of asymptomatic carotid atherosclerosis principal results of the European Lacidipine Study on Atherosclerosis (ELSA), a randomized, double-blind, long-term trial. Circulation. 2002;106(19):2422-7.

33. Sacks FM, Svetkey LP, Vollmer WM, et al. Effects on blood pressure of reduced dietary sodium and the Dietary Approaches to Stop Hypertension (DASH) diet. N Engl J Med. 2001;344(1):3-10.

34. Lewington S, Clarke R, Gizilbash N, Peto R, Collins R, Prospective SC. Age-specific relevance of usual blood pressure to vascular mortality: a meta-analysis of individual data for one million adults in 61 prospective studies. Lancet. 2002;360(9349):1903-13.

35. Hebert PR, Coffey CS, Byrne DW, et al. Treatment of elderly hypertensive patients with epithelial sodium channel inhibitors combined with a thiazide diuretic reduces coronary mortality and sudden cardiac death. J Am Soc Hypertens. 2008;2(5):355-65.

36. Cranston W, Semmence A, Richardson D, Barnett C. Effect of triamterene on elevated arterial pressure. Am Heart J. 1965;70(4):45560.

37. Morin Y, Turmel L, Fortier J. Triamterene: Clinical studies in arterial hypertension. Am Heart J. 1965;69(2):195-9. 